\title{
Effects of Anisodine Hydrobromide on the Cardiovascular and Respiratory Functions in Conscious Dogs
}

This article was published in the following Dove Press journal: Drug Design, Development and Therapy

\author{
Yunlu Liu (iD) ${ }^{1,2}$ \\ Lin Wang' \\ Feng $\mathrm{Wan}^{3}$ \\ $\mathrm{Na}$ Yang
}

'Institute of Laboratory Animal Sciences, Sichuan Academy of Medical Sciences \& Sichuan Provincial People's Hospital, Chengdu, People's Republic of China; ${ }^{2}$ Department of Pharmacy, Sichuan Academy of Medical Sciences \& Sichuan Provincial People's Hospital, Chengdu, People's Republic of China; ${ }^{3}$ College of Pharmacy, Chengdu University of Traditional Chinese Medicine, Chengdu, People's Republic of China
Correspondence: Na Yang Institute of Laboratory Animal Sciences, Sichuan Academy of Medical Sciences \& Sichuan Provincial People's Hospital, Ying Long Community, Zhong he Street Office, High Tech Zone, Chengdu 610212,

People's Republic of China

Tel +86 I3880I 45342

Fax +862867087558

Email nayang@glpcd.com
Purpose: Anisodine hydrobromide (Ani) is isolated from the medicinal plant Anisodus tanguticus (Maxim.) Pascher for clinical use. Although considerable research regarding Ani has been reported, the safety profiles of Ani are currently unknown. This study investigated the cardiorespiratory effects of Ani in conscious dogs to provide clinicians a detailed safety profile of Ani on the cardiorespiratory system.

Materials and Methods: Using the Latin square design, the study was divided into six phases, where in each phase, six telemetered beagle dogs received one dose of normal saline or sotalol hydrochloride or Ani $(0.1,0.4,1.6$, or $6.4 \mathrm{mg} / \mathrm{kg})$. Electrocardiogram, blood pressure (BP) and respiratory parameters were collected before and after administration for 24 hours. Statistical comparisons were performed at scheduled time-points.

Results: The heart rate was significantly increased, $\mathrm{PR}$ and $\mathrm{QT}_{\mathrm{C}} \mathrm{V}$ intervals were significantly shortened in Ani $0.4,1.6,6.4 \mathrm{mg} / \mathrm{kg}$ treatment group after drug administration. Compared with the saline group, a significant increase in heart rate and shortening of $\mathrm{PR}, \mathrm{QT}_{\mathrm{C}} \mathrm{V}$ intervals were observed in the Ani 1.6, $6.4 \mathrm{mg} / \mathrm{kg}$ treatment groups from $5 \mathrm{~min}$ to $4 \mathrm{~h}$ time-points. Diastolic and mean BP were significantly increased in Ani 1.6, $6.4 \mathrm{mg} / \mathrm{kg}$ from $1 \mathrm{~h}$ to $2 \mathrm{~h}$ time-points compared to those of the saline control. Accelerated breathing was observed in the first $20 \mathrm{~min}$ after Ani $0.4,1.6$, and $6.4 \mathrm{mg} / \mathrm{kg}$ treatment, although not statistically significant. Furthermore, no significant differences were observed in any of the corresponding indexes of Ani $0.1 \mathrm{mg} / \mathrm{kg}$ treatment group at different time-points compared to those of the saline group.

Conclusion: Ani may have adverse effects on the cardio-respiratory systems of dogs at doses above $0.4 \mathrm{mg} / \mathrm{kg}$, whereas Ani $0.1 \mathrm{mg} / \mathrm{kg}$ was devoid of potentially deleterious effects on cardiorespiratory function.

Keywords: anisodine hydrobromide, electrocardiogram, blood pressure, cardio-respiratory function, telemetered dogs, safety

\section{Introduction}

Anisodine, a tropane alkaloid extracted from the root of Anisodus tanguticus (Maxim.) Pascher in the family Solanaceae, ${ }^{1}$ has shown significant therapeutic effects on various conditions, such as ocular diseases, ${ }^{2-5}$ motion sickness and migraine, ${ }^{6}$ acute circulatory shock, ${ }^{7}$ and organophosphorus pesticide poisoning. ${ }^{8}$ In view of the unstable chemical properties of anisodine, researchers have developed anisodine hydrobromide (Ani).

Ani acts as non-specific muscarinic cholinoceptor antagonist competing with acetylcholine for binding to the muscarinic cholinergic receptor to block the nerve 
impulse and physiological functions associated with cholinergic neurotransmission. ${ }^{9}$ The autonomic receptors distributed in the cardiac, vascular, and airway smooth muscle are mainly muscarinic cholinoceptors. ${ }^{10-12}$ Thus, the antimuscarinic activity of Ani could potentially lead to various physiological effects on the cardiorespiratory system. Early experimental and clinical studies have reported that structurally-related tropane alkaloids (such as anisodamine, scopolamine, and atropine) have potential undesirable effects on the cardiovascular and respiratory systems. ${ }^{13-18}$ Thus, it is necessary to investigate the effects of Ani on cardiorespiratory function systematically. Additionally, although some drugs, such as antibiotics, tricyclic antidepressants, and antifungal agents do not act on the cardiovascular system directly based on their mechanism of action, nonetheless they have been reported to lead to life-threatening adverse effects, and some patients have suffered serious heart damage after taking these drugs in clinical practice. ${ }^{19-21}$ However, to the best of our knowledge, no previous studies have extensively assessed the cardiovascular and respiratory effects of Ani. To this end, this study was designed to define the effects of Ani on the cardio-respiratory system by following the International Council for Harmonization ( $\mathrm{ICH}$ ) guidelines (S7A, S7B) and the China Food and Drug Administration (CFDA) guidelines, to provide a comprehensive profile of the cardiorespiratory safety of Ani to the clinician.

Electrocardiogram (ECG), blood pressure, and respiratory indices were collected to describe the effects of Ani on the cardiorespiratory system. We especially focused on the prolongation of the QT interval of the ECG, which represents the cardiac repolarization disturbance that can cause torsade de pointes and sudden cardiac death. ${ }^{22}$ Furthermore, indicators of the PR interval and QRS duration of the ECG were also used to evaluate atrioventricular and intraventricular conductivities. In order to validate and define the sensitivity of the experimental system, sotalol hydrochloride (Sol), an antiarrhythmic agent, which is known to prolong the PR interval and QT interval and widen the QRS duration, ${ }^{23}$ was used as the positive control drug. In addition, an implantable telemetry system strongly recommended by $\mathrm{ICH}$ and CFDA in safety pharmacology studies and has been used in the pharmaceutical industry for safety evaluation, ${ }^{24}$ was applied in the present study. Beagle dogs were selected because of the stability of their genetic characteristics and completeness of genetic background information, and feasibility of surgical operation in telemetry experiments. ${ }^{25}$ In addition, respiratory parameters were collected by a telemetry system using electrical impedance technology, a common detection method showing strong correlation with pneumotachograph results in the clinic. ${ }^{26}$

\section{Materials and Methods}

The study was reviewed and approved by the Welfare and Ethics of Experimental Animals Committee of Institute of Laboratory Animal Science, Sichuan Academy of Medical Sciences \& Sichuan Provincial People's Hospital for compliance with Guide for the Care and Use of Laboratory Animals (No. Lunshen2018-016). It was conducted in a research facility accredited by Sichuan Provincial Laboratory Animal Management Committee. The flowchart of the study is detailed in Figure 1.

\section{Animals and Surgical Preparation for Telemetry}

Six beagle dogs (three females and three males, 9-10 months old, 9-12 kg) were obtained from Marshal Biotechnology (Beijing, China). All dogs were housed singly in stainlesssteel canine cages $(1000 \times 1000 \times 2080 \mathrm{~mm})$ for 80 days throughout the study, they were given 25 days to acclimate to the housing environment and team members before the implanted surgery started. All animals were fed a maintenance diet. Filtered mains water was offered adlibitum. Environmental controls were set to maintain the 12hour light-dark cycle (lights on 6:00 AM, off 6:00 PM), $20-25^{\circ} \mathrm{C}$ temperature and $40-70 \%$ humidity range.

The animals were anesthetized with propofol (8-12 mg/ $\mathrm{kg}$ intravascular), and maintained general effect by isoflurane (1.5-5 volume \% in oxygen) inhalation. With the sterile surgical technique, telemetry transmitter (model number TL11M3-D70-PCTR, Data Sciences International [DSI], St. Paul, MN, USA) was implanted in the dogs. The respiratory electrodes were implanted subcutaneously on both sides of the left and right seventh ribs. The ECG electrodes were implanted subcutaneously on the left side of the chest at the intersection of the last rib and the anterior axillary line and on the right side at the middle lower edge of the clavicle. The pressure catheter for blood pressure measurement was implanted in the femoral artery, and the main implant body was fixed in the extra-abdominal oblique muscle. After postoperative care and recovery period were completed, animals were assessed with indices for general physical conditions, including body weight, hematology, blood biochemistry, urine, ECG, blood pressure, and respiratory system, by the 


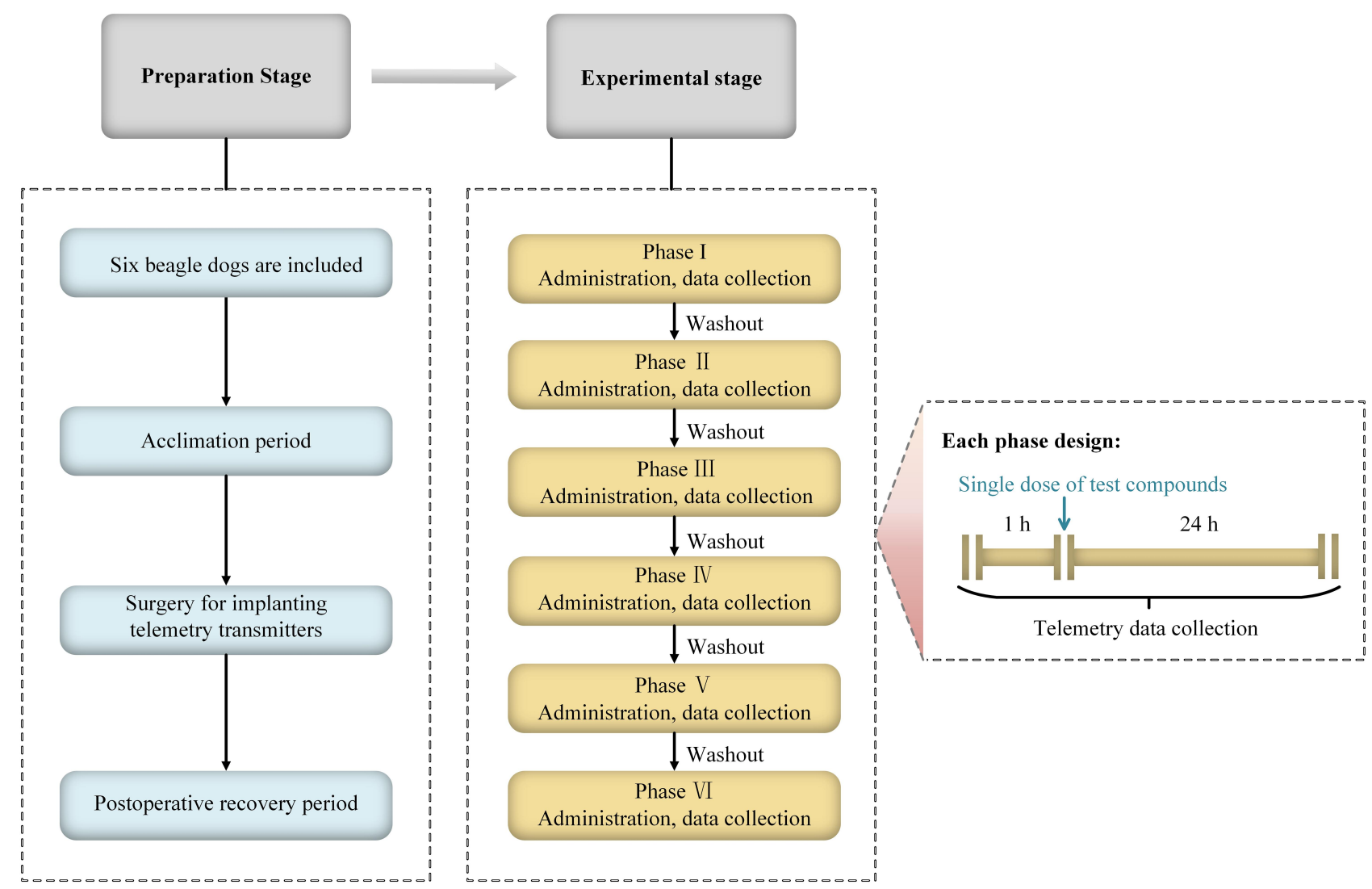

Figure I Flowchart of the study.

veterinarian and transmitter signal to ensure that the animals met the requirements of experimental system for safety pharmacology assessment.

\section{Test Compounds and Dosing}

Ani $(\mathrm{C} 17 \mathrm{H} 21 \mathrm{NO} \cdot \mathrm{HBr}, \mathrm{FW} 400.27$, purity $>99 \%)$ was supplied as a liquid injection preparation by Chengdu NO.1. Pharmaceutical Co., Ltd (Chengdu, China). Sol tablets and normal saline $(0.9 \% \mathrm{w} / \mathrm{v} \mathrm{NaCl})$ were purchased from Lunan Pharmaceutical Group (Linyi, China) and Wuhan Binhu Shuanghe Pharmaceutical Co., Ltd (Wuhan, China), respectively.

The maximum clinical dose of Ani was $0.067 \mathrm{mg} / \mathrm{kg} / \mathrm{d}$ intravenously. Using a body surface area conversion, the effective Ani dose for dogs was $0.12 \mathrm{mg} / \mathrm{kg} / \mathrm{d}$. In the current study, 0.8-, 3.3-, 13.3-, and 53.3-times the effective Ani dose were administered, and defined as the $0.1 \mathrm{mg} / \mathrm{kg}, 0.4 \mathrm{mg} / \mathrm{kg}, 1.6 \mathrm{mg} / \mathrm{kg}$, and $6.4 \mathrm{mg} / \mathrm{kg}$ dose treatment groups, respectively. Furthermore, Sol was selected as the positive control and was dissolved in $0.5 \% \mathrm{w} / \mathrm{v}$ carboxyl methyl cellulose sodium and administered by gavage at dosage of $32 \mathrm{mg} / \mathrm{kg}$. The negative control group received an intravenous injection of an equal volume of normal saline (NS). Additionally, in this study, a single-dose intravenous administration of the Ani and NS was used, the volume and rate of intravenous injection was $2.5 \mathrm{~mL} / \mathrm{kg}$ and $5 \mathrm{~mL} / \mathrm{min}$, respectively. According to the volume, rate and the animal weight, time spent in each injection ranged from 4.5 to $6 \mathrm{~min}$.

\section{Experimental Design}

The experiment used the Latin square design, including six telemetry beagle dogs, six administration groups, and six phases. For each phase, the telemetered dogs were given a single dose of either the NS or Sol $(32 \mathrm{mg} / \mathrm{kg})$ or one of four dose levels of Ani $(0.1,0.4,1.6$, or $6.4 \mathrm{mg} / \mathrm{kg})$. Between each phase, there was a 72-hour washout period (the half-life of intravenous Ani and oral Sol were 1.67 $\mathrm{h}$ and $6.29 \mathrm{~h}$, respectively). Before drug administration, at least a 12-hour fasting time was required.

On treatment days, ECG, blood pressure and respiratory parameters (heart rate, PR interval, QRS duration, QT interval, systolic blood pressure (SYS), diastolic blood 
pressure (DIA), and mean arterial blood pressure (MEAN), tidal volume (TV), minute ventilation volume (MV), and breath rate (BR)) were transmitted as wireless signals by the implanted transmitter to the receiver RMC 1 (DSI, St. Paul, MN, USA) which was located on the cage and converted to conventional units by software (Dataquest OpenART, DSI). A data analysis workstation (PONEMAH Version 5.20, DSI) was used for analyzing the related parameters. All parameters were recorded at least $1 \mathrm{~h}$ prior to and continuously for $24 \mathrm{~h}$ following administration in each experimental phase. For the evaluation of these parameters, the following time-points were used: before and 5, 10, 20, $30 \mathrm{~min}$ and 1, 1.5, 2, 4, 8, 24 $\mathrm{h}$ after dosing. ECG and respiratory waveform morphology were checked manually. Mean values for 2 min were acquired near the scheduled time-points. In the presence of noisy signals caused by animals' movements within the 2-min period, mean values of best quality data over 2 minutes were acquired over a consecutive 10-min period near the tested time-point. As the heart rate would be increased by M-choline receptor blocking by Ani, the QT interval was calculated using the Van de Water's correction formula: ${ }^{27}$ QTcV=QT-0.087× (RR-1), which has a higher accuracy than the $\mathrm{QTcF}$ in high heart rate situations.

Dogs were observed twice daily, and examined for death and general clinical conditions (coat and skin appearance, behavior changes, eating habits, and mental status) before and after treatment. Blinding was achieved by not informing the evaluator of the treatment group for each dog. A standard operating procedure (SOP) for clinical observation was adopted, and the evaluator was trained before the start of the study to follow the SOP for recording observations.

\section{Statistical Analysis}

All data were expressed as mean values \pm standard deviation. All statistical analyses were performed with SPSS statistical software (version 18.0 for Windows, IBM, USA) with twotailed tests and a significance level set at $5 \%(P<0.05)$. All parameters were compared using the repeated measurement ANOVA. If the Mauchly's Test of Spherical test was not statistically significant, the results were analyzed by one-way ANOVA. Conversely, if the spherical test was significant $(P<0.05)$, Greenhouse-Geisser correction was applied and the results were analyzed by one-way ANOVA. Multiple intergroup comparisons at each time-point were performed using a MANOVA, followed by Dunnett's test. Multiple intragroup comparisons between time-points were performed using single-group repeated measures ANOVA, followed by the LSD method.

\section{Results \\ Clinical Observations}

No mortality events were observed. No obvious changes in coat and skin appearance, behavior changes, eating habits, and mental status were observed after treatment in either the negative control group or following administration of Sol $32 \mathrm{mg} / \mathrm{kg}$. In each Ani treated group different degrees of mydriasis were observed after injection, and this symptom was relieved after approximately 24-72 h. Other adverse clinical signs were absent in the Ani groups.

\section{Effects of Ani on ECG in Conscious Dogs}

Changes in heart rate, $\mathrm{PR}$ interval, $\mathrm{QRS}, \mathrm{QT}_{\mathrm{C}} \mathrm{V}$ are shown in Figures 2-5, respectively.

\section{Heart Rate}

In the negative control group, the heart rate slightly increased 5 minutes after of NS administration, which may be related to the tension state of the animals, and then the heart rate slowly decreased to the lowest point at 1.5-2 hours after administration, and slightly increased again at 6 hours to 8 hours after administration. The change of heart rate in each drug (Sol, Ani) treated group differed from that of the negative control group, and the difference was statistically significant $(P<0.01)$. After Sol $32 \mathrm{mg} / \mathrm{kg}$ administration, a continuously slow decrease in heart rate up to 24 -h post-dose was observed, and significant differences were detected at the 1.5, 2, 4, and 24-h time-points after Sol administration compared with the before administration heart rate (either $P<0.01$ or $P<0.05)$. Moreover, heart rate was significantly lower than that in the negative control at the 24-h time-point $(P<0.05)$. Trends in changes in heart rate in the Ani $0.1 \mathrm{mg} / \mathrm{kg}$ group were consistent with those of the negative control group. However, after Ani treatments of 0.4, 1.6, and $6.4 \mathrm{mg} / \mathrm{kg}$, the heart rate of the animals increased rapidly over time, and statistical significances were detected range from $5 \mathrm{~min}$ to $2 \mathrm{~h}$ time-points (either $P<0.01$ or $P<0.05)$. Moreover, heart rate was significantly increased in animals treated with Ani $1.6,6.4 \mathrm{mg} / \mathrm{kg}$ at 5 , $10,20,30 \mathrm{~min}, 1,1.5,2$, and $4 \mathrm{~h}$ time-points, respectively, compared with the heart rates in the negative control group (either $P<0.01$ or $P<0.05$ ). 


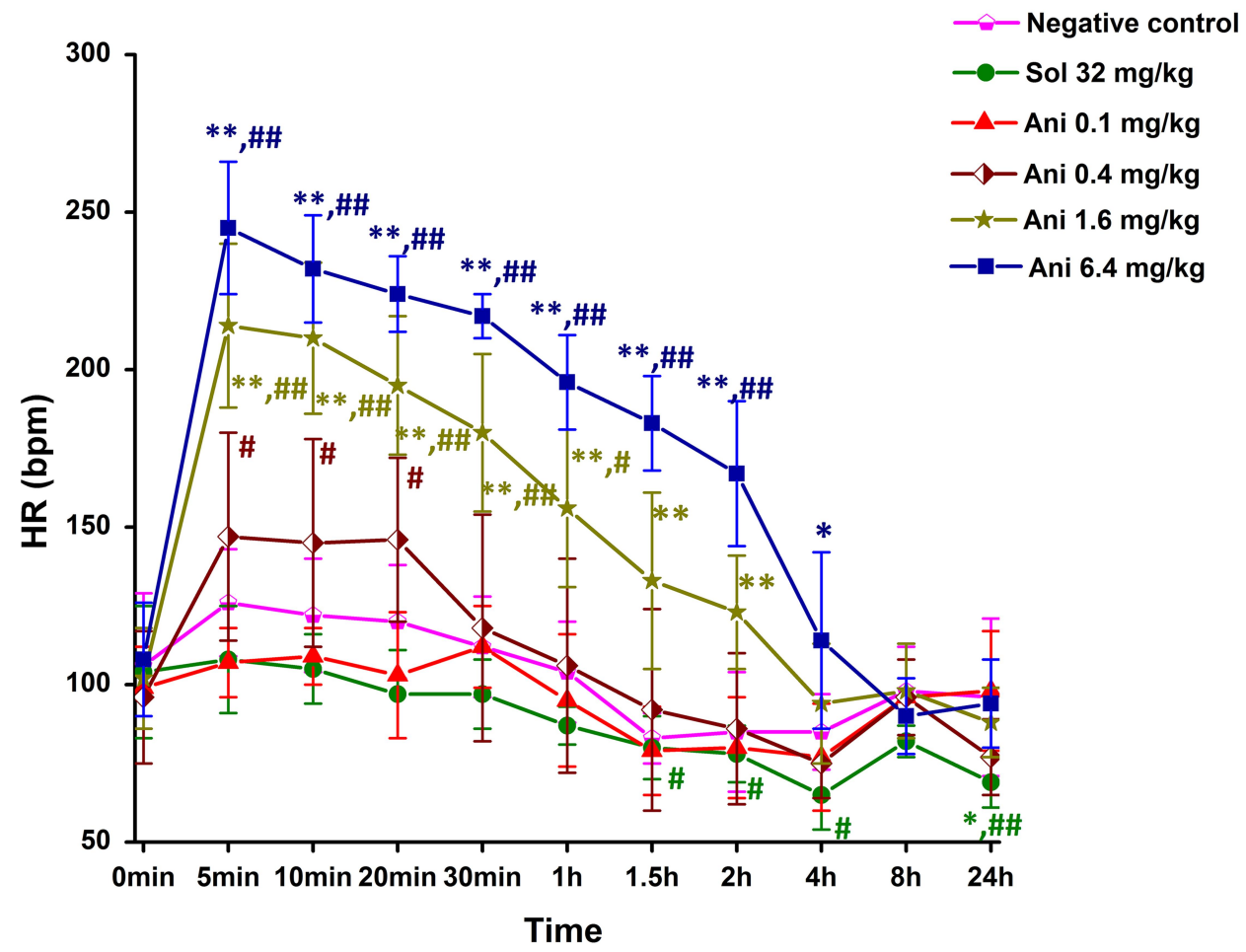

Figure 2 Effects of single intravenous anisodine hydrobromide (Ani) on heart rate (HR). HR in telemetered conscious dogs was measured at pre-dose ( 0 min) and 5 , 10,20 , and 30 minutes and I, I.5, 2, 4, 8 and $24 \mathrm{~h}$ after administration (represented as mean of 6 animals and standard deviation). Statistical results for HR, asterisks denote

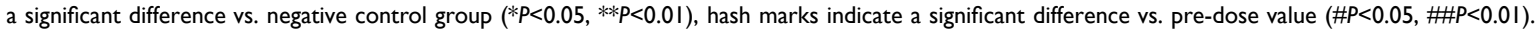

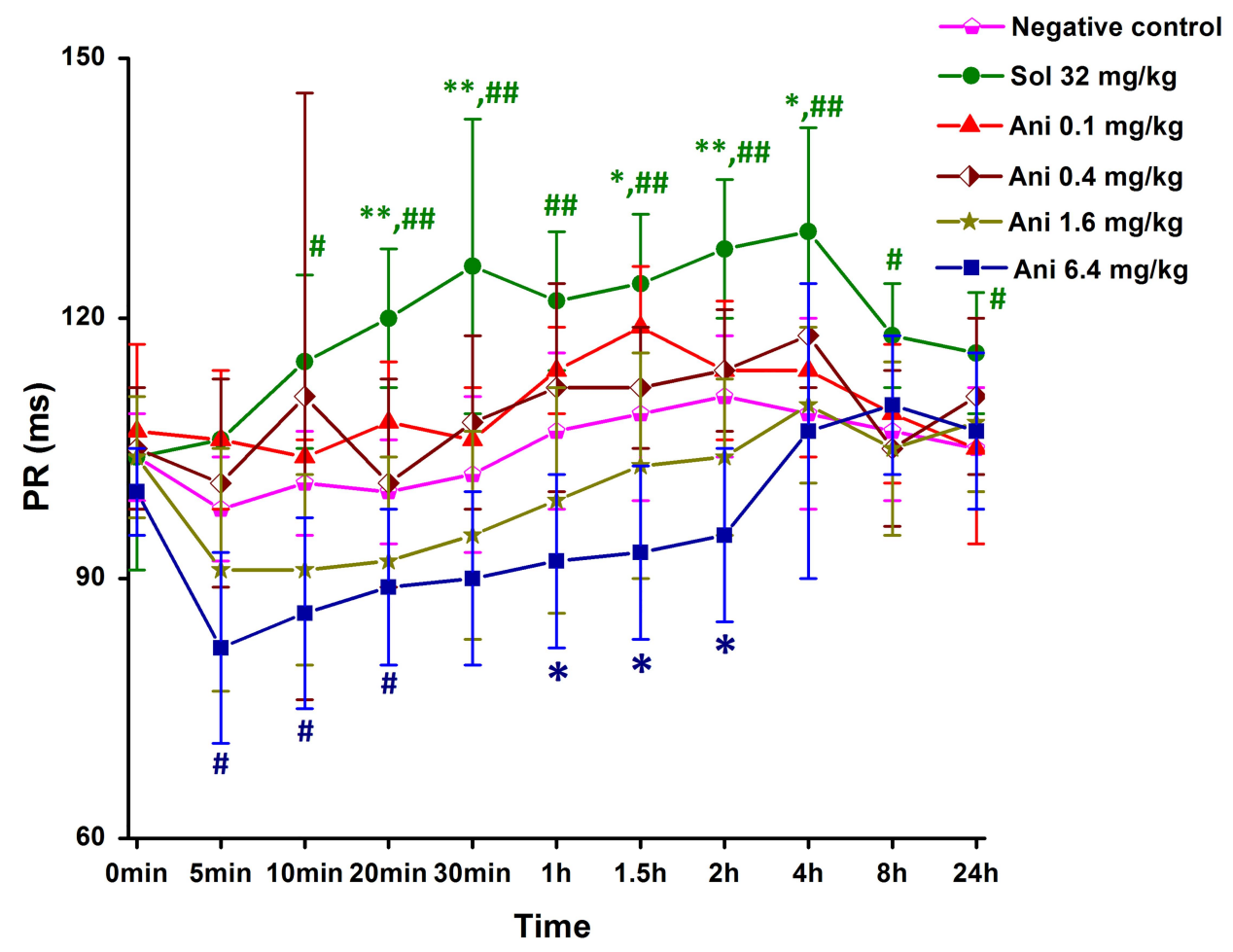

Figure 3 Effects of single intravenous anisodine hydrobromide (Ani) on PR interval. PR interval in telemetered conscious dogs was measured at pre-dose (0 min) and 5, I0, 20, and 30 minutes and I, I.5, 2, 4, 8 and $24 \mathrm{~h}$ after administration (represented as mean of 6 animals and standard deviation). Statistical results for PR interval, asterisks denote a significant difference vs. negative control group $(* P<0.05, * * P<0.01)$, hash marks indicate a significant difference vs. pre-dose value (\#P<0.05, \#P<0.01). 


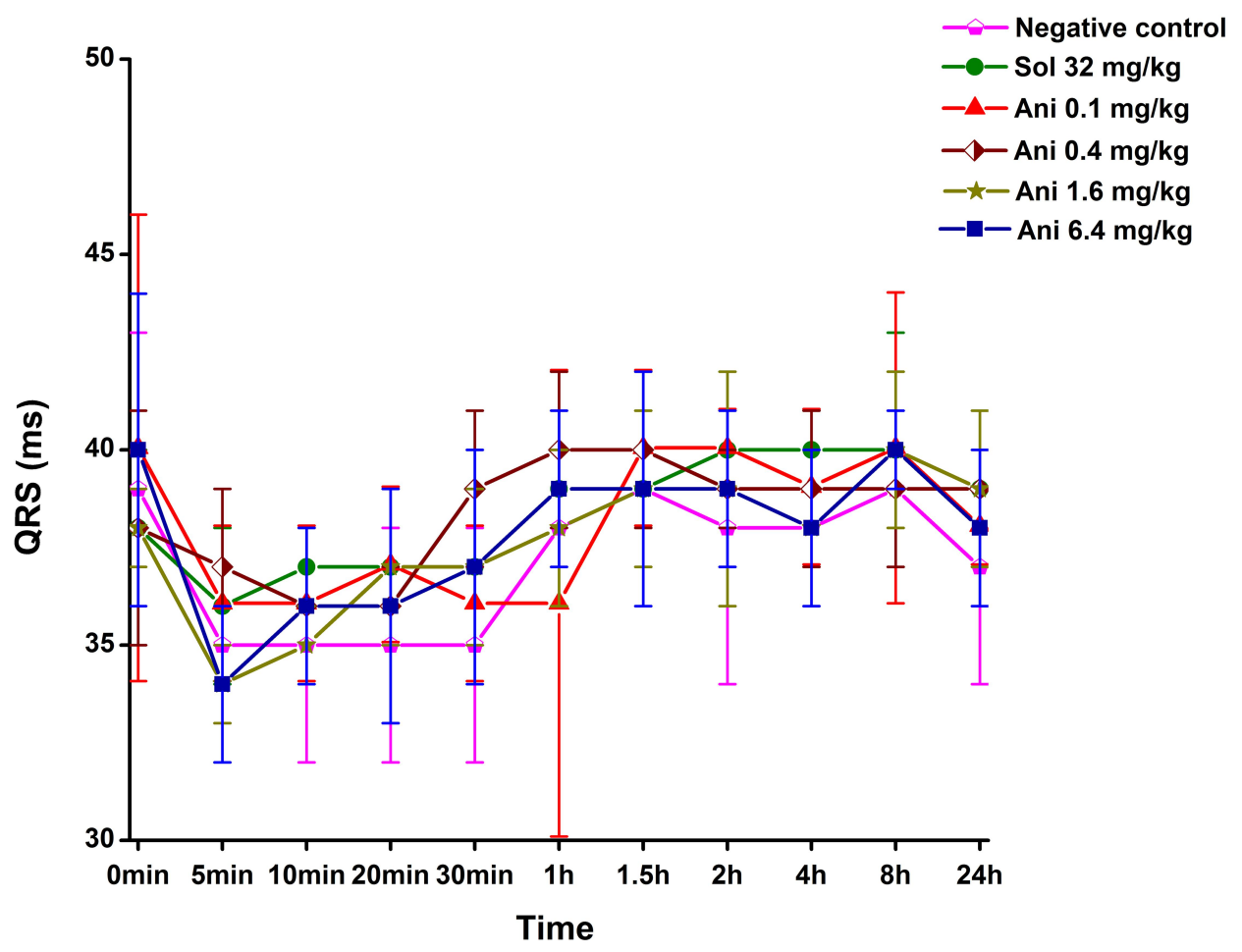

Figure 4 Effects of single intravenous anisodine hydrobromide (Ani) on QRS complex. QRS complex interval in telemetered conscious dogs was measured at pre-dose (0 $\mathrm{min}$ ) and 5, 10, 20, and 30 minutes and I, I.5, 2, 4, 8 and $24 \mathrm{~h}$ after administration (represented as mean of 6 animals and standard deviation). Statistical results for QRS complex, no significant differences were observed.

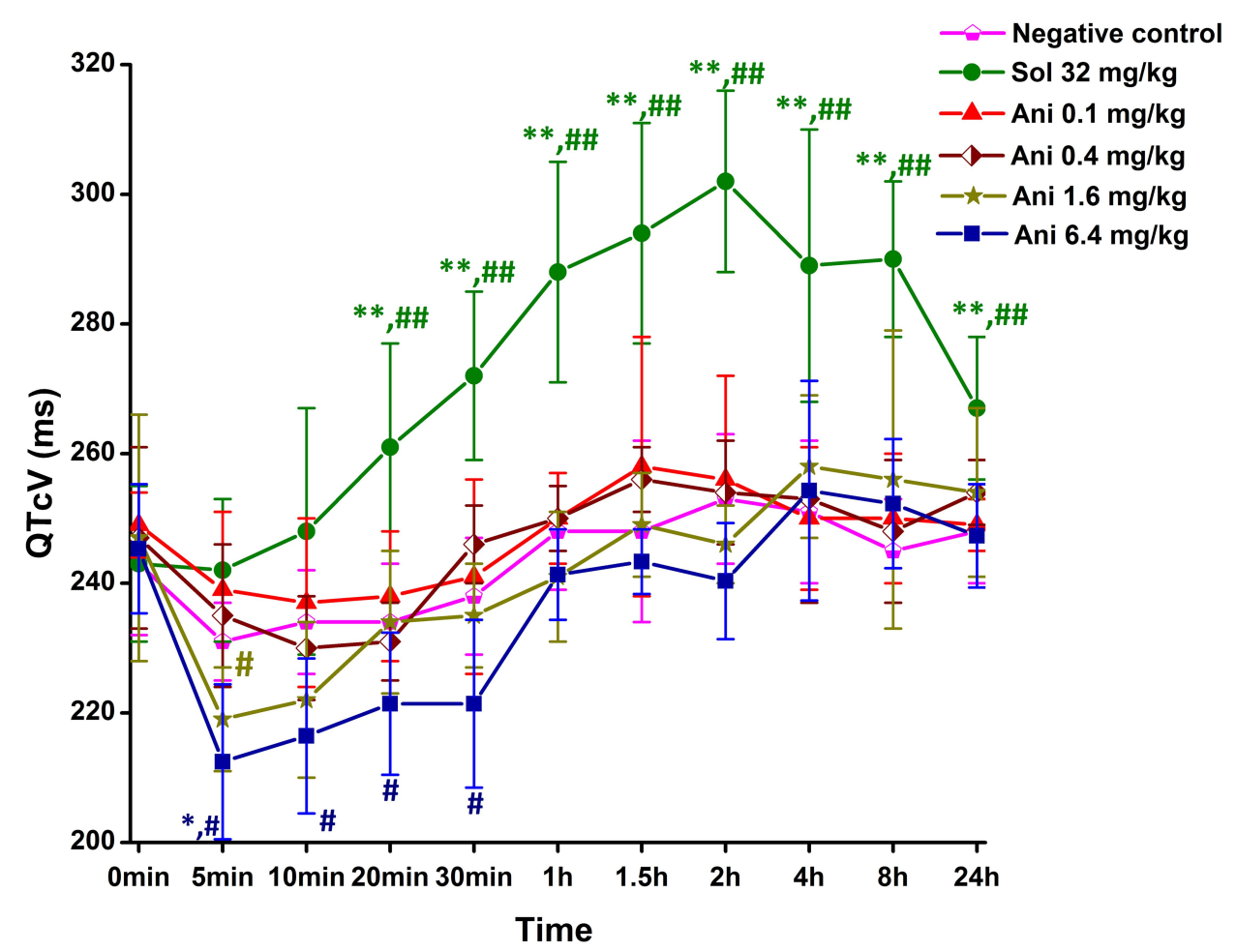

Figure 5 Effects of single intravenous anisodine hydrobromide (Ani) on QTCV. QTCV in telemetered conscious dogs was measured at pre-dose (0 min) and 5, I0, 20, and 30 minutes and I, I.5, 2, 4, 8 and $24 \mathrm{~h}$ after administration (represented as mean of 6 animals and standard deviation). Statistical results for $Q T_{C} V$, asterisks denote a significant difference vs. negative control group $(* P<0.05$, $* * P<0.01)$, hash marks indicate a significant difference vs. pre-dose value (\#P<0.05, \#P<0.0I). 


\section{PR Interval}

The PR interval in the negative control group was stable over the scheduled time period, and there was no significant difference between the pre-treatment and posttreatment time-points. The change in PR interval with time in each drug (Sol, Ani) treated group differed significantly from that in the negative control group $(P<0.01)$. Compared to pre-dose level, the PR intervals after Sol treatment gradually increased from $10 \mathrm{~min}$ to $24 \mathrm{~h}$ timepoint (either $P<0.01$ or $P<0.05$ ). Compared with the values at each time-point of negative controls, Sol prolonged the PR interval at the 20 and $30 \mathrm{~min}$ and at the 1.5, 2, 4 h scheduled time-points (either $P<0.01$ or $P<0.05$ ).

No significant changes in the PR interval could be observed at each post Ani $0.1 \mathrm{mg} / \mathrm{kg}$ dose time-point compared to negative controls. After dosing Ani $6.4 \mathrm{mg} / \mathrm{kg}$, the PR interval of the animals shortened rapidly over time with significance from $5 \mathrm{~min}$ to $20 \mathrm{~min}$ time-points $(P<0.05)$. Compared with the values at each time-point of the negative control, treatment with $6.4 \mathrm{mg} / \mathrm{kg}$ Ani could induce significant shortening of PR interval at the $1,1.5$, and $2 \mathrm{~h}$ post-dose time-points $(P<0.05)$.

\section{QRS-Complex Durations}

QRS-complex durations showed little change with time in each drug (Sol, Ani) treated group. Compared with the values at each time-point of negative control, there were not significant changes of QRS-complex duration for either Sol- or Ani-treated groups.

\section{QTCV Interval}

In the negative control group, the $\mathrm{QT}_{\mathrm{C}} \mathrm{V}$ interval was slightly shortened due to the slight acceleration of heart rate over the first 30 minutes after treatment, however, there were no significant differences between each timepoint or before treatment values. The change in $\mathrm{QT}_{\mathrm{C}}$ $\mathrm{V}$ interval at each time-point for each drug (Sol, Ani) group was different from that of the negative control group, and the difference was statistically significant $(P<0.01)$. After administration with Sol $32 \mathrm{mg} / \mathrm{kg}$, the $\mathrm{QT}_{\mathrm{C}} \mathrm{V}$ interval was significantly prolonged from $20 \mathrm{~min}$ to the 24-h time-point with a peak at the 2-h time-point on intragroup analysis (all $P<0.01$ ). A significant prolongation of the $\mathrm{QT}_{\mathrm{C}} \mathrm{V}$ interval in Sol group was observed at 20, 30 min, 1, 1.5, 2, 4, 8, and $24 \mathrm{~h}$ time-points compared to $\mathrm{QT}_{\mathrm{C}} \mathrm{V}$ intervals measured in the negative control group $(P<0.01)$. No changes in the $\mathrm{QT}_{\mathrm{C}} \mathrm{V}$ interval at each timepoint following Ani $0.1 \mathrm{mg} / \mathrm{kg}$ were observed compared to the negative control animals. After dosing Ani 1.6 and $6.4 \mathrm{mg} / \mathrm{kg}$, the QTCV interval of the animals shortened rapidly over time, and returned to pre-dose values from approximately $10 \mathrm{~min}$ to $1 \mathrm{~h}$ post-administration $(P<0.05)$, and the $\mathrm{QT}_{\mathrm{C}} \mathrm{V}$ interval was significantly shorter than that in the negative control group for the Ani $6.4 \mathrm{mg} / \mathrm{kg}$ treatment group at the 5-min post-dose time-point $(P<0.05)$.

\section{Effects of Ani on Blood Pressure in Conscious Dogs}

Changes in SYS, DIA, and MEAN are shown in Figures 6-8, respectively. In the negative control group, the SYS was slightly increased in the first 30 minutes after administration, which may have been related to the tension state of the animals, and then slowly decreased, reaching a low point at $1.5 \mathrm{~h}$ after administration, and then slightly increased at about the 2-h time-point, and then continuously decreased to the lowest point at $8 \mathrm{~h}$ after administration. The change of SYS over time in each drug (Sol, Ani) treated group was similar to that of the negative controls $(P>0.05)$. Compared with the SYS values at each time-point of negative control, there were no differences after Sol or Ani treatment.

The trend in DIA observed over time in the negative control group was similar to that of observed for SYS. Sol and Ani $0.1 \mathrm{mg} / \mathrm{kg}$ treated groups showed similar trends for DIA as the negative control group, and no significant changes were observed at each time-point tested compared to the negative controls. The DIA was much higher at the 1-, 1.5-, 2-h post-dose time-points in the animals treated with Ani 1.6 and $6.4 \mathrm{mg} / \mathrm{kg}$ compared to those in the negative control (either $P<0.01$ or $P<0.05$ ), and returned to normal at around the $4 \mathrm{~h}$ time-point. In comparison to the negative controls, significant increases in MEAN were observed in the Ani 1.6 and $6.4 \mathrm{mg} / \mathrm{kg}$ treatment groups at the $1-$ and 1.5-h post-dose time-points (either $P<0.01$ or $P<0.05$ ).

\section{Effects of Ani on Respiratory Indices in Conscious Dogs}

Changes in BR, TV, MV are shown in Figures 9-11, respectively. In the negative control group, the BR gradually slowed to the lowest point at $1.5 \mathrm{~h}$ after administration, and increased slightly from $6 \mathrm{~h}$ to $8 \mathrm{~h}$ after administration. Changes observed in BR over time in each drug (Sol, Ani) treatment group was similar to that in the negative control group, and compared with negative controls, the BR of animals receiving Ani 0.4, 1.6, and $6.4 \mathrm{mg} / \mathrm{kg}$ was higher in first $20 \mathrm{~min}$ after administration, 


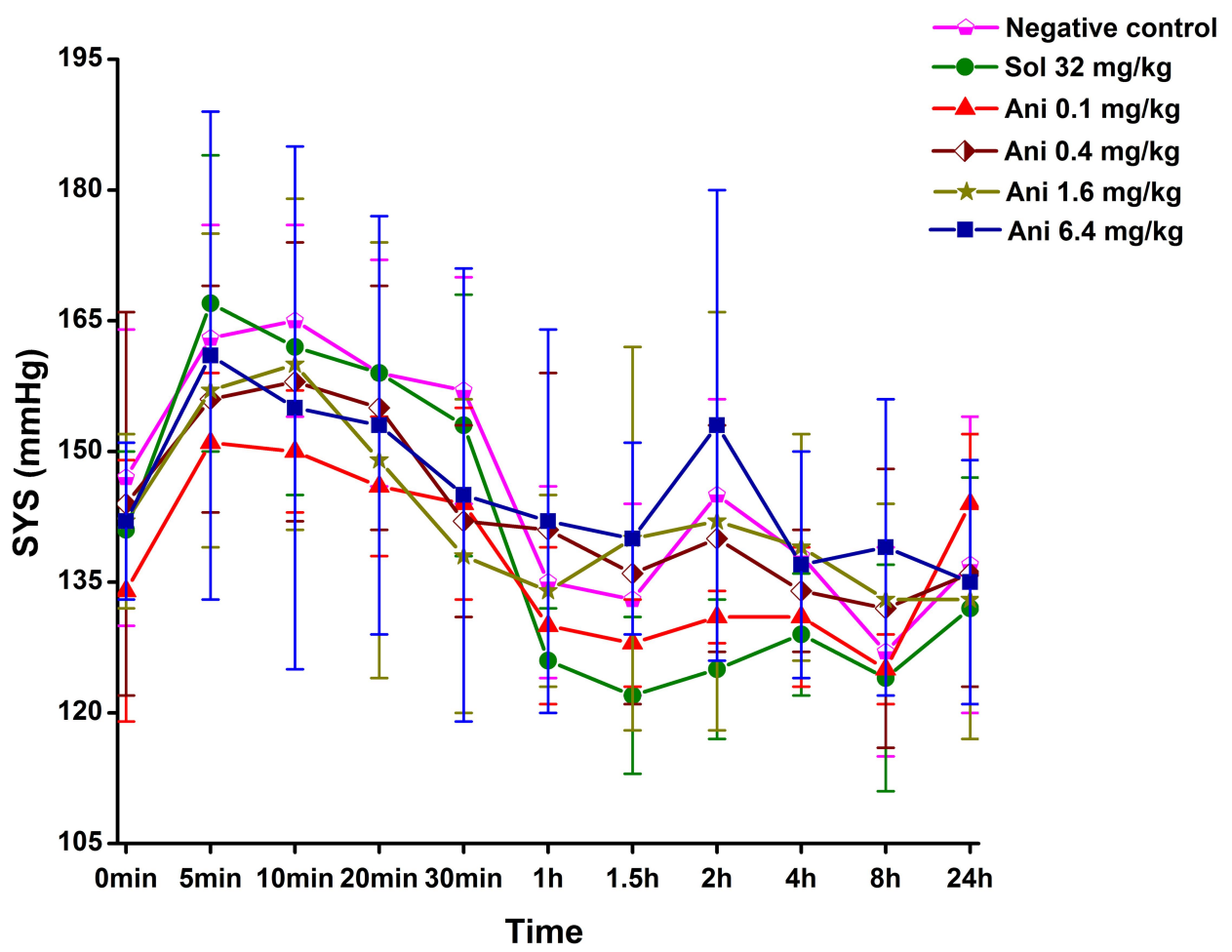

Figure 6 Effects of single intravenous anisodine hydrobromide (Ani) on systolic blood pressure (SYS). SYS in telemetered conscious dogs was measured at pre-dose (0 min) and 5, 10, 20, and 30 minutes and I, I.5, 2, 4, 8 and $24 \mathrm{~h}$ after administration (represented as mean of 6 animals and standard deviation). Statistical results for SYS, no significant differences were observed.

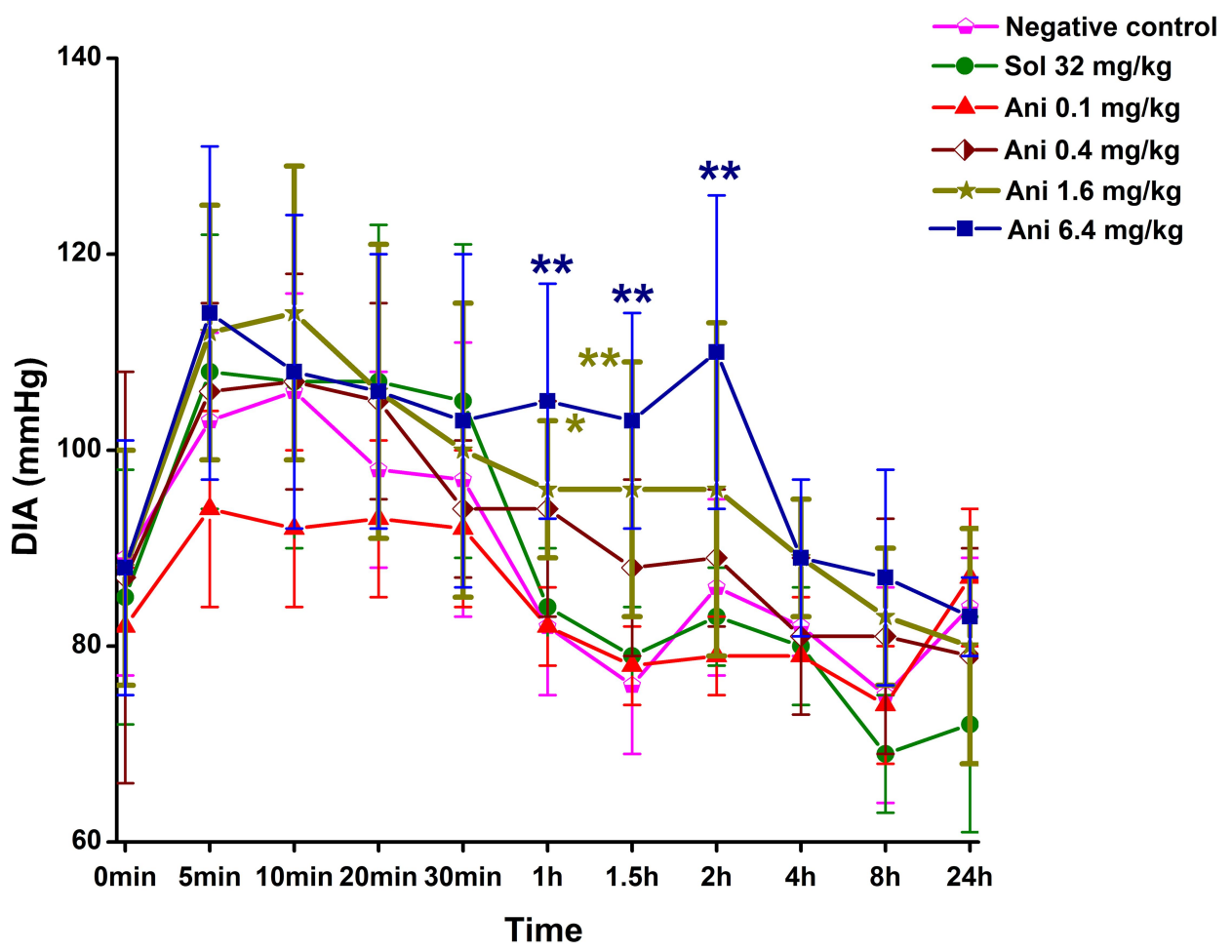

Figure 7 Effects of single intravenous anisodine hydrobromide (Ani) on diastolic blood pressure (DIA). DIA in telemetered conscious dogs was measured at pre-dose (0 $\min$ ) and 5, 10, 20, and 30 minutes and I, I.5, 2, 4, 8 and $24 \mathrm{~h}$ after administration (represented as mean of 6 animals and standard deviation). Statistical results for DIA, asterisks denote a significant difference vs. negative control group $(* P<0.05$, $* * P<0.01)$. 


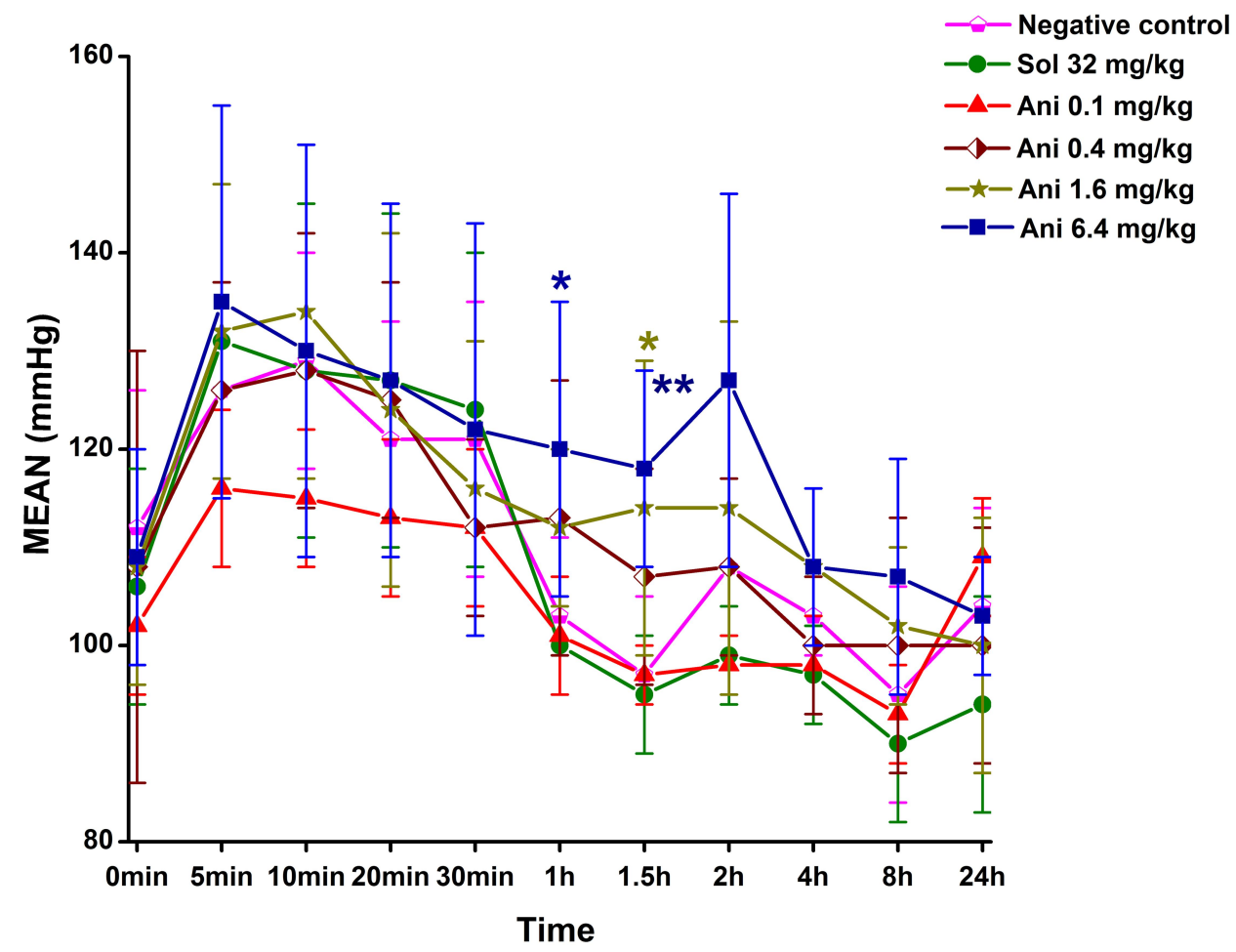

Figure 8 Effects of single intravenous anisodine hydrobromide (Ani) on mean arterial blood pressure (MEAN). MEAN in telemetered conscious dogs was measured at predose $(0 \mathrm{~min})$ and 5, 10, 20, and 30 minutes and I, I.5, 2, 4, 8 and $24 \mathrm{~h}$ after administration (represented as mean of 6 animals and standard deviation). Statistical results for MEAN, asterisks denote a significant difference vs. negative control group $(* P<0.05, * * P<0.01)$.

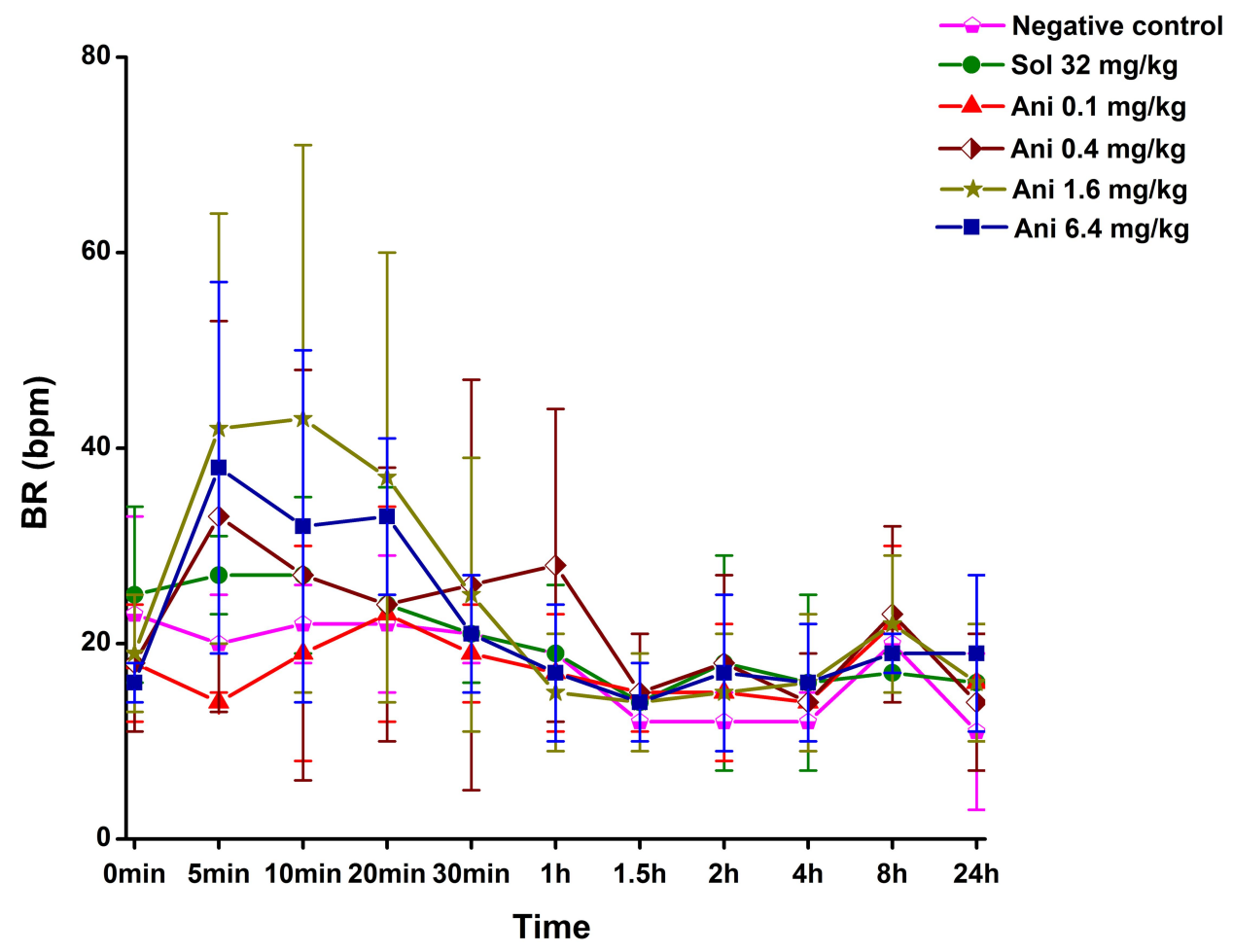

Figure 9 Effects of single intravenous anisodine hydrobromide (Ani) on breath rate (BR). BR in telemetered conscious dogs was measured at pre-dose ( 0 min) and $5,10,20$, and 30 minutes and I, I.5, 2, 4, 8 and $24 \mathrm{~h}$ after administration (represented as mean of 6 animals and standard deviation). Statistical results for BR, no significant differences were observed. 


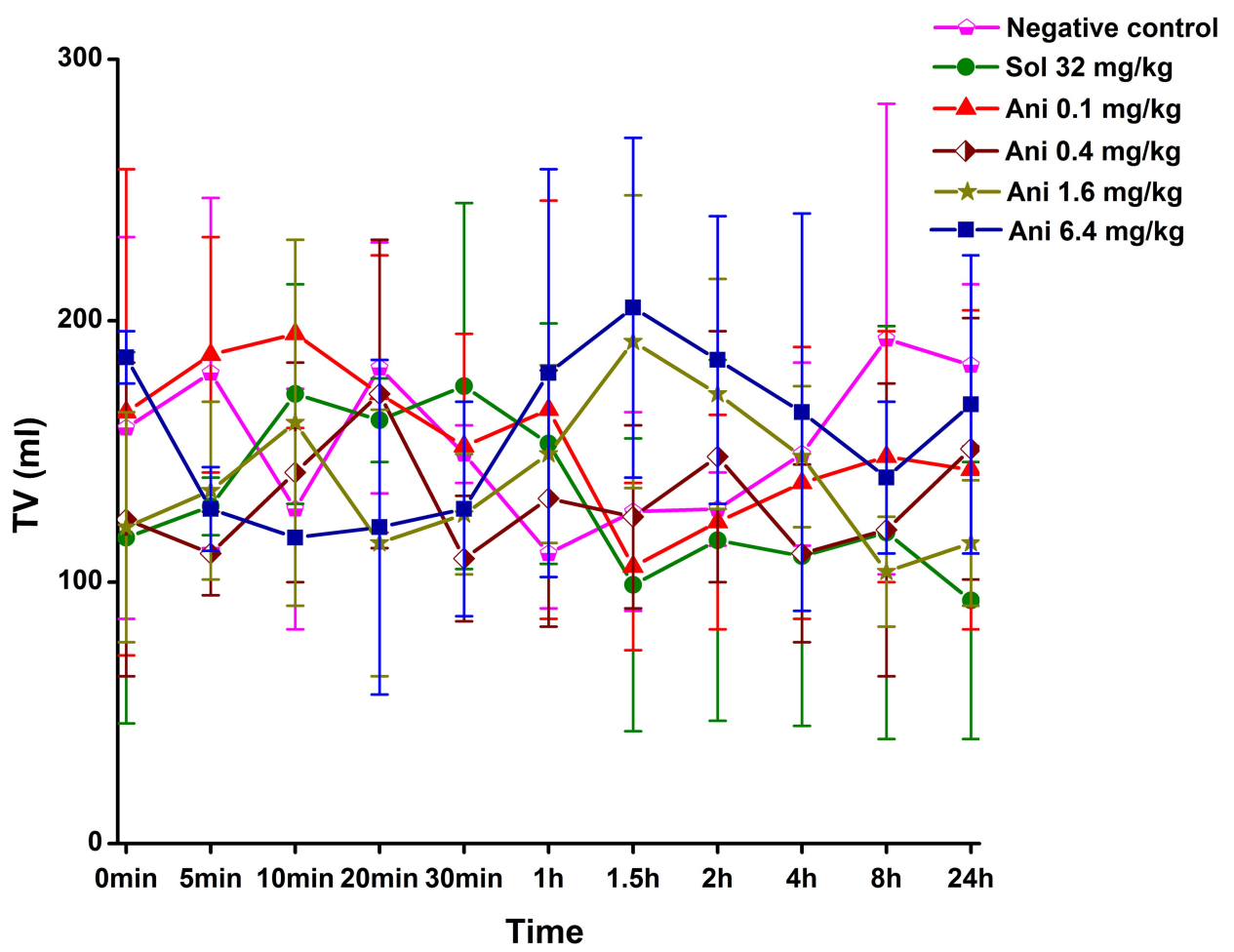

Figure 10 Effects of single intravenous anisodine hydrobromide (Ani) on tidal volume (TV). TV in telemetered conscious dogs was measured at pre-dose ( 0 min) and 5 , I0, 20 , and 30 minutes and I, I.5, 2, 4, 8 and $24 \mathrm{~h}$ after administration (represented as mean of 6 animals and standard deviation). Statistical results for TV, no significant differences were observed.

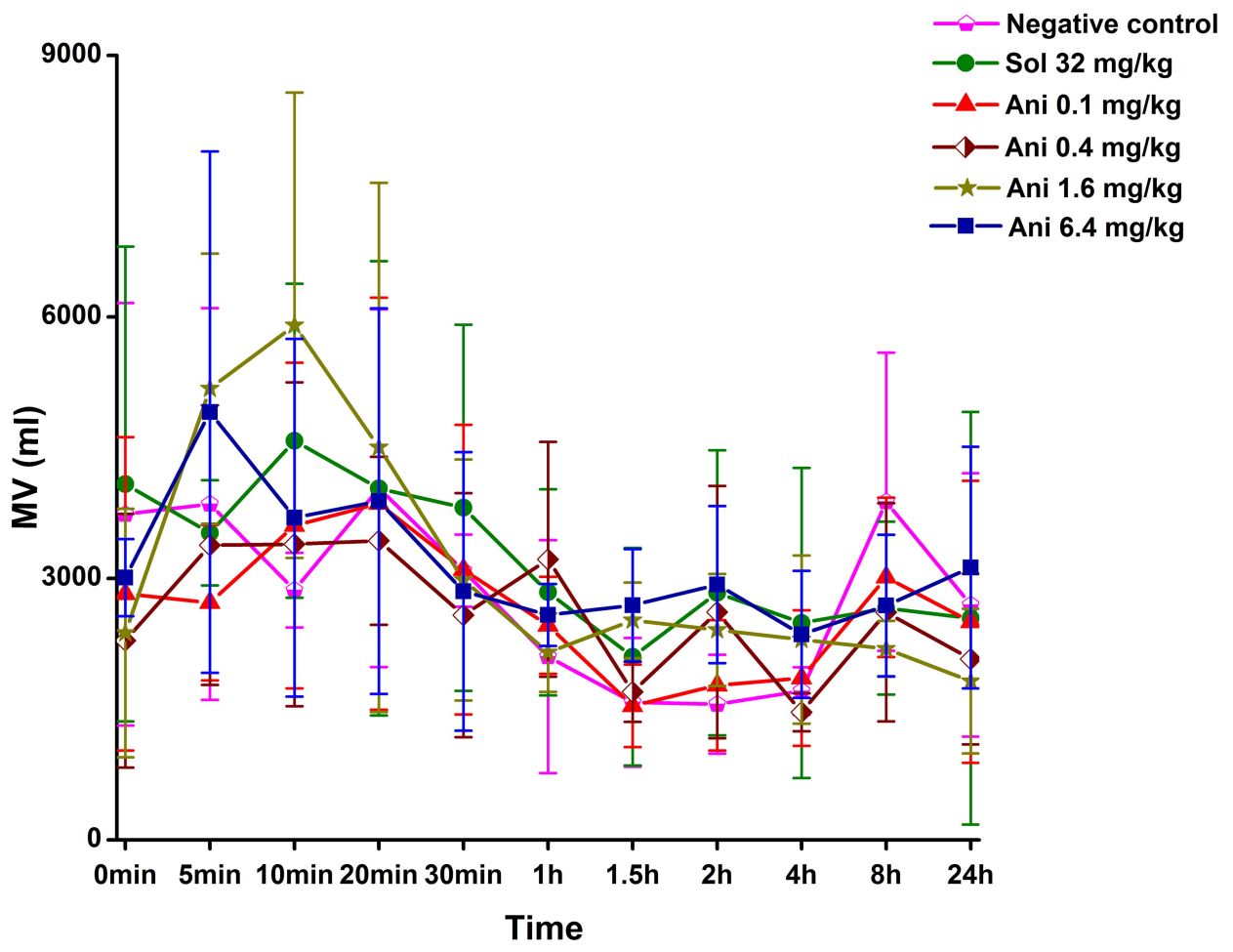

Figure I I Effects of single intravenous anisodine hydrobromide (Ani) on minute ventilation volume (MV). MV in telemetered conscious dogs was measured at pre-dose ( 0 min) and 5, 10, 20, and 30 minutes and I, I.5, 2, 4, 8 and 24 h after administration (represented as mean of 6 animals and standard deviation). Statistical results for MV, no significant differences were observed. 
albeit the increased BR observed were no statistically significant, there was no significant difference in TV or MV between the Sol or Ani treatment groups and the negative control group.

\section{Discussion}

Ani has been demonstrated to possess strong central and peripheral anticholinergic activity. ${ }^{28,29}$ Similarly, Ani has been reported to ameliorate memory impairment in a chronic cerebral hypoperfusion rat model by repairing the imbalance between monoamine neurotransmitter and cholinergic dysfunction. ${ }^{30}$ Further, Ani compound preparation (a preparation contains Ani, procaine and hyaluronidase) has shown the ability to inhibit the proliferation of epithelium and collagen fibers, to improve blood supply to tissues, and to prevent scar formation in mouse skin. ${ }^{31}$ A liquid chromatography-electrospray ionization tandem mass spectrometry method was used to identify the metabolites of Ani in rats, and the results indicated that five metabolites (norscopine, scopine, $\alpha$-hydroxytropic acid, noranisodine, and hydroxyanisodine) as well as the parent drug were identified in feces, four metabolites (norscopine, scopine, hydroxyanisodine and anisodine $\mathrm{N}$-oxide) and the parent drug were found in plasma, while, three new metabolites (dimethoxyanisodine, tetrahydroxyanisodine, and trihydroxy-methoxyanisodine) were detected in urine. ${ }^{32}$ Although such detailed information about Ani has been reported, a comprehensive understanding of the safety pharmacology profile of Ani and most critically, and of any undesirable effects on life-supporting functions in Ani is still absent. Thus, we detected the cardiovascular and respiratory effects in conscious telemetry dogs following a single intravenous administration of Ani using a telemetry device to collect ECG, blood pressure, and respiratory data. Additionally, clinical observations were also introduced in the present study.

The dog equivalent dose of intravenous injection of Ani in the clinic was $0.12 \mathrm{mg} / \mathrm{kg} / \mathrm{d}$. Previous studies have also revealed that depression, vomiting, and salivation could be induced by compound anisodine (a compound preparation made from Ani and procaine hydrochloride) administered subcutaneously at a dose of $40.4 \mathrm{mg} / \mathrm{kg}$, and no significant abnormality was observed at dosages below $4.04 \mathrm{mg} / \mathrm{kg} .{ }^{33}$ Based on the principle of safety pharmacology studies, which suggest that the lowest tested dose should be equivalent to the proposed therapeutic dose and the highest dose should produce a moderate toxic reaction, ${ }^{34}$ four doses $(0.1,0.4,1.6$, and $6.4 \mathrm{mg} / \mathrm{kg})$ of Ani were defined for this study to provide safety pharmacology information and included doses exceeding the therapeutic range.

In this study, a reversible mydriasis was observed in all Ani treatment groups. It has been well documented that Ani has effects on the parasympathetic nervous system through its activity as a non-specific muscarinic cholinoceptor antagonist. Thus, we conjectured that the mydriatic activity was a result of the relaxation of sphincter and the ciliary muscle due to the antimuscarinic effect of Ani. ${ }^{35}$

In the current study, the assessment of the cardiovascular effects of Ani was limited to ECG and blood pressure measurements. The ECG parameters included heart rate, PR interval, QRS duration, and QT interval. Due to an inverse, non-linear relationship between QT interval and heart rate, the variations in heart rate among individuals can confound the evaluation of the effect of drugs on the QT interval. ${ }^{36}$ Therefore, we corrected the QT interval for heart rate using Van de Water's formulae $\left(\mathrm{QT}_{\mathrm{C}} \mathrm{V}\right)$. Our results demonstrated that Sol treatment could decrease heart rate and prolong the $\mathrm{PR}$ and $\mathrm{QT}_{\mathrm{C}} \mathrm{V}$ intervals, which were induced by increasing the cardiac action potential duration and the effective refractory period, and by inhibiting the conduction time at the sinoatrial and atrioventricular nodes. ${ }^{37}$ As the positive control, the sensitivity of the test system was validated by the efficacy of the above ECG changes elicited by Sol. It is well known that vagal nerve activity has a great impact on the automaticity of heart due to its dominant distribution at the sinus node, atrioventricular junction, atrial muscle. Physiologically, acetylcholine released from the cardiac vagus ganglion acts on the muscarinic acetylcholine receptor located on the myocardial cell membrane, and induces negative chronotropic, negative conductive, and inotropic effects on heart. ${ }^{38,39}$ As a muscarinic acetylcholine receptor antagonist, Ani competes with acetylcholine released from the vagus nerve for binding to the muscarinic cholinergic receptor, thus relieving the inhibitory action of vagal nerve stimulation on the heart. Consequently, a significantly increased heart rate and shortened PR interval were detected in the Ani $1.6 \mathrm{mg} / \mathrm{kg}$ or $6.4 \mathrm{mg} / \mathrm{kg}$ treatment groups. Additionally, the shortened $\mathrm{QT}_{\mathrm{C}} \mathrm{V}$ interval in Ani $1.6,6.4 \mathrm{mg} / \mathrm{kg}$ treatment groups may be compatible with the effect of increased heart rate. ${ }^{36}$ In particular, none of Ani dosages showed a potential to prolong the $\mathrm{QT}_{\mathrm{C}}$ $\mathrm{V}$ interval.

Systolic, diastolic and mean blood pressures were evaluated in this study. The results showed that both 
DIA and MEAN were significantly increased at the same time-points tested after Ani 1.6, $6.4 \mathrm{mg} / \mathrm{kg}$ administration. However, the effect of Ani on SYS was not observed. It is well known that the heart rate can directly affect the length of cardiac cycle, especially the duration of diastolic phase. As the heart rate accelerated, the shortening of diastole has been reported to be more obvious than that of systole. ${ }^{40}$ Thus, in diastole, the reduced blood flow deriving from the large artery to the peripheral artery led to a consequent increase in DIA with an increase in residual blood volume in the aorta. ${ }^{41}$ Conversely, the increased arterial blood pressure resulted in high blood flow speed, and as a consequence, there was still sufficient blood flow to the periphery during systole, $^{42}$ which lead to insignificant changes in SYS. Moreover, according to the calculation formula $(\mathrm{MEAN}=\mathrm{DIA}+1 / 3$ pulse pressure), the MEAN was greatly affected by DIA and pulse pressure difference, ${ }^{43}$ therefore, the change in MEAN was essentially similar to that of DIA.

We used BR, TV, and MV values to assess drug effects on the respiratory system. No statistically significant differences in these parameters were detected in any of the Ani-treated groups. However, interestingly, a trend in accelerated BR was detected within the first 20 minutes after Ani 0.4, 1.6, and $6.4 \mathrm{mg} / \mathrm{kg}$ administration. A previous study reported that Ani could increase the rate of phrenic nerve discharges (PND) and the rate of inspiratory neuron firing in the nucleus tractus solitarius, as well as reduce the time of inspiration, expiration, and spikes in each PND. ${ }^{44}$ Furthermore, Ani has also been reported to be able to partially antagonize the respiratory depression induced by morphine, which may be a consequence of the stimulatory activity of Ani on the respiratory center through the cholinergic muscarinic pathway. ${ }^{44}$ Thus, we assume that Ani may exert activity on respiratory function, although the absence of statistical significance of the changes observed in this study may be attributed to the small sample number.

The present study held some limitations. Firstly, we used the Van de Water's formula to correct the QT interval. Although the formula is considered to be the optimal choice for evaluating QT intervals over a wide range of HR in dogs, a fluctuation in the average QT interval is still inevitable. ${ }^{45}$ In order to resolve this problem and to develop a more accurate alternative formula, further study of QT correction methods is warranted, which will not only consider the influence of the heart rate but also the effect due to sex, genetic background, or body position. Secondly, in reference to different safety pharmacology studies, ${ }^{46-48}$ young and healthy beagle dogs were included in our study, while for many patients experiencing age-related morbidities, both age and disease status are usually considered risk factors for adverse drug reactions. ${ }^{49}$ Thus, any potential cardiorespiratory adverse effects due to Ani treatment in older patients with disease requires further elucidation. In addition, the small sample size in this study was adopted to reduce animal usage and experimental costs, as a consequence any additional significant drug-induced effects might not have been detected (as in the results of respiratory parameters in our study). Therefore, further studies are needed, including more animals, and animals of various ages, to comprehensively understand the effect of Ani on organ functions.

\section{Conclusion}

Taken together, our study has provided detailed information of the effect of Ani on the cardiorespiratory system. The dosage of Ani $0.1 \mathrm{mg} / \mathrm{kg}$ did not present any adverse effects on ventricular repolarization, atrio/intra-ventricular conduction, blood pressure, or ventilation functions, however, the dosage of Ani used should be strictly controlled in the clinically due to the undesirable effects on the cardiorespiratory system observed in our beagle dog model at dosages greater than $0.4 \mathrm{mg} / \mathrm{kg}$.

\section{Abbreviations}

Ani, anisodine hydrobromide; BP, blood pressure; ICH, International Council for Harmonization; CFDA, China Food and Drug Administration; ECG, Electrocardiogram; Sol, sotalol hydrochloride; NS, normal saline; SYS, systolic blood pressure; DIA, diastolic blood pressure; MEAN, mean arterial blood pressure; TV, tidal volume; MV, minute ventilation volume; $\mathrm{BR}$, breath rate; SOP, standard operating procedure; PND, phrenic nerve discharges.

\section{Funding}

This study was supported by the science and technology support plan of Sichuan province under Grant (No. 2016SZ0027).

\section{Disclosure}

Yunlu Liu, Lin Wang, Feng Wanand Na Yang report grants from the Science and Technology support plan of Sichuan province, during the conduct of the study. The authors report no other potential conflicts of interest in this work. 


\section{References}

1. Cardillo AB, Otalvaro AÁM, Busto VD, et al. Scopolamine, anisodamine and hyoscyamine production by Brugmansia candida hairy root cultures in bioreactors. Process Biochem. 2010;45 (9):1577-1581. doi:10.1016/j.procbio.2010.06.002

2. Liu W-D, Chen -L-L, Shen C-Y, et al. Neuroprotective effect of compound anisodine in a mouse model with chronic ocular hypertension. Chin Med J. 2015;128(19):2652-2657. doi:10.4103/ 0366-6999.166043

3. Wang W, Huang Y, Zhang J, et al. Efficacy of cytidine-5'-diphospbocholine combined with compound anisodine in the treatment of early optic nerve contusion. Eye Sci. 2012;27(1):37-40.

4. Wu X-J, Gao F, Liu X, et al. Observation on therapeutic efficacy of rt-PA intravenous thrombolysis combined with compound anisodine injection on central retinal artery occlusion. Exp Ther Med. 2016;12 (4):2617-2621. doi:10.3892/etm.2016.3681

5. Zhang YH, He MN, Yu XL, et al. Deffect of compound anisodine combined with cobamamide on treating patients with ischemic optic neuropathy and their hemodynamics and hemorheology. Acta Medica Mediterr. 2019;35(3):1463-1467.

6. Chang J, Xie W, Wang L, et al. An efficient approach to the asymmetric total synthesis of (-)-anisodine. Eur J Med Chem. 2006;41 (3):397-400. doi:10.1016/j.ejmech.2005.12.001

7. Varma DR, Yue TL. Adrenoceptor blocking properties of atropine-like agents anisodamine and anisodine on brain and cardiovascular tissues of rats. $\mathrm{Br} J$ Pharmacol. 1986;87(3):587-594. doi:10.1111/j.1476-5381.1986.tb10201.x

8. Tian F, Li C, Wang X, et al. Comparative study on pharmacokinetics of a series of anticholinergics, atropine, anisodamine, anisodine, scopolamine and tiotropium in rats. Eur $J$ Drug Metab Pharmacokinet 2015;40(3):245-253. doi:10.1007/s13318-014-0192-y

9. Lee* K-H, Morris-natschke SL, Brattlie J, et al. Chapter 6 modern drug discovery from chinese materia medica used in traditional chinese medicine. Tradit Chin Med. 2013;81-134.

10. Deighton NM, Motomura S, Borquez D, et al. Muscarinic cholinoceptors in the human heart: demonstration, subclassification, and distribution. Naunyn Schmiedebergs Arch Pharmacol. 1990;341 (1):14-21.

11. Ikeda T, Anisuzzaman A, Yoshiki H, et al. Regional quantification of muscarinic acetylcholine receptors and $\beta$-adrenoceptors in human airways. $B r J$ Pharmacol. 2012;166(6):1804-1814. doi:10.1111/ j.1476-5381.2012.01881.x

12. Eglen RM, Whiting RL. Heterogeneity of vascular muscarinic receptors. J Auton Pharmacol. 1990;10(4):233-246. doi:10.1111/ j.1474-8673.1990.tb00023.x

13. Breslin F, McFadden E, Ingram R, et al. Effects of atropine on respiratory heat loss in asthma. J Appl Physiol. 1980;48 (4):619-623. doi:10.1152/jappl.1980.48.4.619

14. Chang S-L, Lin W-L, Weng C-H, et al. Atropine use may lead to post-operative respiratory acidosis in neonates receiving ductal ligation: a retrospective cohort study. Pediatr Neonatol. 2018;59 (2):136-140. doi:10.1016/j.pedneo.2017.04.005

15. Cooper M, Abinader E. Atropine-induced ventricular fibrillation: case report and review of the literature. Am Heart J. 1979;97 (2):225-228. doi:10.1016/0002-8703(79)90360-0

16. Schweitzer P, Mark H. The effect of atropine on cardiac arrhythmias and conduction. Part 1. Am Heart J. 1980;100(1):119-127. doi:10.1016/0002-8703(80)90287-2

17. Suzuki S, Nonaka A, Abe F. Effect of esmolol on cardiovascular responses induced by scopolamine butylbromide. Masui. 2005;54 (11): 1277-1281.

18. Vesalainen RK, Tahvanainen KU, Kaila TJ, et al. Effects of low-dose transdermal scopolamine on autonomic cardiovascular control in healthy young subjects. Clin Physiol. 1997;17(2):135-148. doi:10.1046/j.1365-2281.1997.t01-1-02020.x
19. Crumb W, Cavero II. QT interval prolongation by non-cardiovascular drugs: issues and solutions for novel drug development. Pharm Sci Technol Today. 1999;2(7):270-280. doi:10.1016/S1461-5347(99) 00172-8

20. Cubeddu LX. Iatrogenic QT abnormalities and fatal arrhythmias: mechanisms and clinical significance. Curr Cardiol Rev. 2009;5 (3):166-176. doi:10.2174/157340309788970397

21. Straus SMJM, Sturkenboom MCJM, Bleumink GS, et al. Noncardiac QTc-prolonging drugs and the risk of sudden cardiac death. Eur Heart J. 2005;26(19):2007-2012. doi:10.1093/eurheartj/ehi312

22. Fermini B, Fossa AA. The impact of drug-induced QT interval prolongation on drug discovery and development. Nat Rev Drug Discov. 2003;2(6):439-447. doi:10.1038/nrd1108

23. Ibrahim F, El-Brashy A, El-Awady M, et al. Development of a validated spectrofluorimetric method for assay of sotalol hydrochloride in tablets and human plasma: application for stability-indicating studies. Open Chem. 2019;17(1):64-74. doi:10.1515/chem-2019-0008

24. Baird TJ, Bailie M, Patrick DJ, et al. Influence of surgically implantable telemetry solutions on in-life and post-mortem toxicology endpoints. J Pharmacol Toxicol Methods. 2013;67(3):148-161. doi:10.1016/j.vascn.2013.02.006

25. Friedrichs GS, Patmore L, Bass A. Non-clinical evaluation of ventricular repolarization (ICH S7B): results of an interim survey of international pharmaceutical companies. $J$ Pharmacol Toxicol Methods. 2005;52(1):6-11. doi:10.1016/j.vasen.2005.05.001

26. Kearney K, Metea M, Gleason T, et al. Evaluation of respiratory function in freely moving beagle dogs using implanted impedance technology. J Pharmacol Toxicol Methods. 2010;62(2):119-126. doi:10.1016/j.vasen.2010.06.004

27. Vandewater A, Verheyen J, Xhonneux R, et al. An improved method to correct the QT interval of the electrocardiogram for changes in heart rate. J Pharmacol Methods. 1989;22(3):207-217. doi:10.1016/ 0160-5402(89)90015-6

28. Pan SY, Han YF. Learning deficits induced by 4 belladonna alkaloids are preferentially attenuated by tacrine. Acta Pharmacol Sin. 2000;21 (2):124-130.

29. Peng JZ, Jin LR, Chen XY, et al. Central effects of anisodamine, atropine, anisodine and scopolamine after intraventricular injection. Zhongguo Yao Li Xue Bao. 1983;4(2):81-87.

30. Chen D, Peng C, Xie X, et al. Low dose of anisodine hydrobromide induced neuroprotective effects in chronic cerebral hypoperfusion rats. CNS Neurol Disord Drug Targets. 2018;16(10):1111-1119. doi: $10.2174 / 1871527316666171026114043$

31. Song C, Shen W, He Q. An experimental study on compound anisodine III for softening scar of mouse skin after burn. Zhonghua Yan Ke Za Zhi. 1996;32(3):176-178.

32. Chen H, Chen Y, Du P, et al. Structural elucidation of in vivo and in vitro metabolites of anisodine by liquid chromatography-tandem mass spectrometry. J Pharm Biomed Anal. 2007;44(3):773-778. doi:10.1016/j.jpba.2007.01.038

33. Chen H, Shi Y, Liu YQ, et al. Effect of compound anisodine on central nervous system of beagle dogs. Chin J Pharmacol Toxicol. 1997;11(02):144.

34. Food, Drug Administration HHS. International conference on harmonisation; guidance on S7A safety pharmacology studies for human pharmaceuticals; availability. Notice. Fed Regist. 2001;66 (135):36791-36792.

35. Kovalcuka L, Birgele E, Bandere D, et al. Comparison of the effects of topical and systemic atropine sulfate on intraocular pressure and pupil diameter in the normal canine eye. Vet Ophthalmol. 2015;18 (1):43-49. doi:10.1111/vop.12138

36. Segal L, Roger V, Williams C, et al. Effects of adjuvant systems on the cardiovascular and respiratory functions in telemetered conscious dogs and anaesthetised rats. Regul Toxicol Pharmacol. 2015;73 (1):116-125. doi:10.1016/j.yrtph.2015.06.003 
37. Kirchhof P, Milberg P, Eckardt L, et al. Effect of sotalol and acute ventricular dilatation on action potential duration and dispersion of repolarization after defibrillation shocks. J Cardiovasc Pharmacol. 2003;41(4):640-648. doi:10.1097/00005344-200304000-00018

38. Pelleg A, Mitsuoka T, Mazgalev T, et al. Interacting negative chronotropic effects of adenosine and the vagus nerve on the canine sinus node. Cardiovasc Res. 1988;22(1):55-61. doi:10.1093/cvr/22.1.55

39. Yonehara N, Saito K, Uchida S, et al. Effects of muscarinic agonists and antagonists on the negative chronotropic responses to the vagus nerve stimulation. Jpn J Pharmacol. 1979;29(5):797-799. doi:10.1254/jjp.29.797

40. Perim RR, Signorelli GR, Myers J, et al. The slope of the oxygen pulse curve does not depend on the maximal heart rate in elite soccer players. Clinics. 2011;66(5):829-835. doi:10.1590/S180759322011000500020

41. Park JIK, Heikhmakhtiar AK, Kim CH, et al. The effect of heart failure and left ventricular assist device treatment on right ventricular mechanics: a computational study. Biomed Eng Online. 2018;17:62.

42. Organizers SIdFAotXVRPMFI. Società Italiana di fisiologia abstracts of the XV riunione primaverile (spring meeting) 25-27 may 1988, Firenze, Italy. Pflugers Arch. 1989;414(3):S39-S70. doi:10.1007/ BF00584643

43. Baker LB, Lang JA, Kenney WL. Quantitative analysis of serum sodium concentration after prolonged running in the heat. $J \mathrm{Appl}$ Physiol. 2008;105(1):91-99. doi:10.1152/japplphysiol.00130.2008
44. Xu W, Chen XY. Effects of anisodine on respiratory center. Zhongguo Yao Li Xue Bao. 1994;15(2):165-169.

45. Soloviev MV, Hamlin RL, Shellhammer LJ, et al. Variations in hemodynamic parameters and ECG in healthy, conscious, freely moving telemetrized beagle dogs. Cardiovasc Toxicol. 2006;6 (1):51-62. doi:10.1385/CT:6:1:51

46. Yuan H, Zhao J, Guo J, et al. Comparison of freely-moving telemetry Chinese Miniature Experiment Pigs (CMEPs) to beagle dogs in cardiovascular safety pharmacology studies. J Pharmacol Toxicol Methods. 2014;70(1):19-28. doi:10.1016/j.vascn.2014.03.172

47. Bassett L, Troncy E, Pouliot M, et al. Telemetry video-electroencephalography (EEG) in rats, dogs and non-human primates: methods in follow-up safety pharmacology seizure liability assessments. J Pharmacol Toxicol Methods. 2014;70(3):230-240. doi:10.1016/j.vascn.2014.07.005

48. Hayes AW, Pressman P, Moser P, et al. Regulatory safety pharmacology evaluation of BIA 10-2474. J Pharmacol Toxicol Methods. 2020;102:106677. doi:10.1016/j.vascn.2020.106677

49. Ross CJD, Visscher H, Sistonen J, et al. The canadian pharmacogenomics network for drug safety: a model for safety pharmacology. Thyroid. 2010;20(7):681-687. doi:10.1089/thy.2010.1642

\section{Publish your work in this journal}

Drug Design, Development and Therapy is an international, peerreviewed open-access journal that spans the spectrum of drug design and development through to clinical applications. Clinical outcomes, patient safety, and programs for the development and effective, safe, and sustained use of medicines are a feature of the journal, which has also been accepted for indexing on PubMed Central. The manuscript management system is completely online and includes a very quick and fair peer-review system, which is all easy to use. Visit http://www. dovepress.com/testimonials.php to read real quotes from published authors. 